\title{
Dispersion and Burning Behavior of Hydrogen Released in a Full-Scale Residential Garage in the Presence and Absence of Conventional Automobiles - Supplemental Video Materials
}

\author{
William M. Pitts, Jiann C. Yang, Kuldeep Prasad, Marco Fernandez \\ National Institute of Standards and Technology, \\ Gaithersburg, MD 20899, USA \\ William.Pitts@nist.gov \\ Jiann.Yang@nist.gov \\ Kuldeep.Prasad@nist.gov \\ Marco.Fernandez@nist.gov \\ Data DOI: https://doi.org/10.18434/T4/1500893
}

Key words: fire safety; fuel-cell; garage; hydrogen.

Accepted: July 2, 2018

Published: July 11, 2018

https://doi.org/10.6028/jres.123.014

\section{Summary}

The supplemental materials reported here provide standard high-definition (HD), high-speed, and infrared videos of the 13 full-scale hydrogen dispersion and burning experiments on which Ref. [1] is based. References [1] and [2] provide detailed descriptions of the experimental conditions under which these videos were taken. The videos show different burning dynamics of various hydrogen/air mixtures in the presence and absence of vehicles parked inside the garage. The test identification (ID) numbers associated with the filenames of the data folders correspond to those in Table 1 of Ref. [1]. The number, types, and locations of the videos varies from test-to-test.

\section{Data Specifications}

\begin{tabular}{ll}
\hline NIST Operating Unit(s) & Engineering Laboratory and Fire Research Division \\
\hline Format & Mpg or divx \\
\hline Instrument & Standard high-definition, high-speed, and infrared video cameras \\
\hline Spatial or Temporal Elements & N/A \\
\hline
\end{tabular}




\begin{tabular}{ll}
\hline Data Dictionary & $\begin{array}{l}\text { https://www.nist.gov/el/fire-research-division-73300/dispersion-and- } \\
\text { burning-behavior-hydrogen-released-full-scale }\end{array}$ \\
\hline \multirow{2}{*}{ Accessibility } & $\begin{array}{l}\text { All datasets submitted to Journal of Research of NIST are publicly } \\
\text { available. }\end{array}$ \\
\hline \multirow{3}{*}{ License } & $\begin{array}{l}\text { The videos were produced under NIST contract number } \\
\text { SB134109SE0612 and are not subject to copyright protection within } \\
\text { the United States. }\end{array}$ \\
\hline
\end{tabular}

\section{Methods}

The experiments from which the videos were obtained were conducted at Southwest Research Institute (SwRI), San Antonio, Texas under contract to NIST [1,2]. The experimental series was part of the NIST Hydrogen Fire Safety program. The experiments were conducted using a specially constructed stand-alone garage with the garage door closed. Hydrogen was released through a distribution port located flush with the floor at the center of the garage. Several tests were run in which a conventional automobile (various makes and models) with an empty gasoline tank and all windows and doors closed were parked in the garage centered over the hydrogen release. The hydrogen release scenario assumed a constant leak rate sufficient to release $5 \mathrm{~kg}$ (a typical amount for full tanks on current hydrogen-fueled automobiles) in $1 \mathrm{~h}$. When the hydrogen concentration reached a specified value at a specific location near the garage ceiling, ignition of the hydrogen/air mixture was initiated using an $80 \mathrm{~J}$ squib charge. The entire period during the burning process was recorded using digital hand-held still cameras with video capability, standard high-definition (HD) video cameras, a Raytheon Model TVS-620U infrared (IR) video camera ${ }^{1}$, and a Vision Research Phantom v5.1C high-speed camera operating at $1 \mathrm{kHz}$. At various times, cameras were placed inside the test garage (protected by a plastic housing) near the floor in the rear right corner (HD camera), at the side windows of the garage viewing the ignition area or the center region (HD and/or IR), and at outside positions located at various distances and angles from the garage (HD, high-speed, and digital hand-held cameras).

\section{Impact}

The videos, which are supplemental materials to Ref. [1], together with Refs. [1, 2] will provide hydrogen fire safety data for future standard and code development for residential garages for hydrogen fuel-cell vehicles to mitigate fire hazards.

\section{Acknowledgments}

The authors would like to thank Dr. Matthew Blais, Ms. Alexandra Joyce, and the technical support staff of SwRI for obtaining the videos as part of the deliverables to NIST under contract.

\section{References}

[1] Pitts WM, Yang JC, Blais M, Joyce A (2012) Dispersion and burning behavior of hydrogen released in a full-scale residential garage in the presence and absence of conventional automobiles. International Journal of Hydrogen Energy 37(22):17457-17469. https://doi.org/10.1016/j.ijhydene.2012.03.074

[2] Blais M, Joyce A (2010) Hydrogen Release and Combustion Measurements in a Full Scale Garage. (National Institute of Standards and Technology, Gaithersburg, MD), NIST Grant/Contract Report (GCR) 10-929. Available at https://www.nist.gov/publications/hydrogen-release-and-combustion-measurements-full-scale-garage

${ }^{1}$ Certain commercial equipment, instruments, or materials are identified in this paper in order to specify the experimental procedure adequately. Such identification is not intended to imply recommendation or endorsement by the National Institute of Standards and Technology, nor is it intended to imply that the materials or equipment identified are necessarily the best available for the purpose. 
About the authors: William M. Pitts is a research chemist in the Fire Research Division at NIST. Jiann C. Yang is Deputy Division Chief in the Fire Research Division at NIST. Kuldeep Prasad is a research mechanical engineer in the Fire Research Division at NIST. Marco Fernandez is an engineering technician in the Fire Research Division at NIST. The National Institute of Standards and Technology is an agency of the U.S. Department of Commerce. 